\title{
Reported rapes at a hospital rape centre: Demographic and clinical profiles
}

\author{
Kees Lammers, Lindi Martin, Donavan Andrews, Soraya Seedat
}

To the Editor: Figures for the period 2008/2009 indicate a 10\% rise in the number of reported sexual offences compared with figures for $2007 / 2008 .^{1}$ The increase may be partly attributable to the recent version of the act regulating sexual offences: the Criminal Law (Sexual Offences and Related Matters) Amendment Act, Act 32 of 2007 (Act). In this Act, the definition of rape has been broadened to include the non-consensual vaginal, oral or anal penetration of any person, regardless of gender, with any object. ${ }^{2}$ South Africa has one of the highest incidences of rape in the world and the most violent types of rape in the world, with gang rape and severe physical injury to rape victims commonly occurring. ${ }^{3,4}$ Moreover, the consequences of rape potentially include many medical and psychological difficulties, such as unwanted pregnancy, risk of sexually transmitted infections (STIs), genital and physical injury, and psychological disturbance e.g. post-traumatic stress disorder, major depression, increased risk of suicidal ideation, and alcohol and drug abuse problems. ${ }^{5,6}$ Rape survivors have specific health needs, ideally met by providing integrated and holistic post-rape services, including the provision of pregnancy testing and prevention, termination of pregnancy, testing and treatment of STIs and injuries, and psychosocial counselling. ${ }^{7}$ Rape survivors strongly value the availability of HIV prophylaxis, an understanding health care provider, access to and receiving counselling, and thorough physical examination, emphasising the need for a holistic approach to post-rape care. ${ }^{8,9}$ The Act aims to provide certain services to survivors of sexual assault to minimise or prevent further traumatisation, yet the only medical service conditionally provided to rape survivors is the provision of post-exposure prophylaxis $(\mathrm{PEP}) .^{2}$

We aimed to replicate and build on a previous record review of female rape survivors ${ }^{4}$ by providing an overview of the demographic, clinical, and rape characteristics of female and male children and adult rape survivors presenting to a rape centre in the Western Cape. We aimed to provide evidence and

Department of Psychology, University of Amsterdam, The Netherlands K Lammers, BA Hons (Psychology)

MRC Unit on Anxiety and Stress Disorders, Department of Psychiatry, Stellenbosch University, Tygerberg, W Cape

L Martin, MA (Psychology)

South African Research Chair in Post-traumatic Stress Disorder, South African Research Chairs Initiative, Department of Science and Technology/National Research Foundation and MRC Unit on Anxiety and Stress Disorders, Department of Psychiatry, Stellenbosch University

S Seedat, MB ChB, MMed (Psych), FCPsych, PhD

Karl Bremer Hospital Rape Clinic, Parow, W Cape

D Andrews, MD support for the ongoing call for the provision of effective and integrated post-rape services for rape survivors.

\section{Methods}

We conducted a retrospective review of patient records for all male and female rape survivors, including children and adults, who presented to the Karl Bremer Hospital Rape Centre from 1 August 2007 to 31 July 2008. Standard procedures at this centre include a medical and forensic examination and treatment of physical injuries and STIs. A 28-day course of prophylactic antiretroviral medication is also provided to rape survivors presenting within 72 hours of the reported rape.

Data from patient records included age of rape survivors, day of the week that the rape was reported, alcohol and drug use of the rape survivor, number of perpetrators involved, whether the perpetrator was known/unknown to the rape survivor, injuries sustained during the rape, HIV status of the rape survivor, and the type of rape committed (anal and/or vaginal). Data were analysed on SPSS version 17. Descriptive statistics (means and standard deviations (SDs)) were computed for the variables of interest. To determine whether any significant differences were evident between males and females in terms of the variables of interest, the chisquare test or Fisher's exact test were used where appropriate. Ethical permission to conduct the study was obtained from the Stellenbosch University ethics committee.

\section{Results}

A total of 1132 confirmed rape cases were identified, comprising 1013 female (mean age 20.7 years, SD 11.2) and 119 male (mean age 11.3 years, SD 8.7) rape cases, respectively (Table I). The mean age for the total sample was 19.7 years (SD 11.4), with the youngest survivor being a newborn and the eldest 78 years old; $34.1 \%$ were $<15$ years old. Most patient visits occurred on a Sunday and Monday. There was clinical evidence of alcohol use in $20.7 \%$ of rape survivors, and of drug use in $3.0 \%$. In $33.3 \%$ of gang rapes, survivors had consumed alcohol, and drug use was reported in $7.5 \%$ of the gang rapes. Previous rapes were reported by $6.9 \%$ of alcohol users and by $6.3 \%$ of drug users. In $10 \%$ of cases, there were $\geq 2$ perpetrators, ranging from 1 to 8 . In $67.8 \%$ of cases, the perpetrator was known to the survivor, and in survivors $<15$ years old, $84.5 \%$ had been raped previously by someone known to them. A significant difference between males and females was found in terms of genital and/or anal injuries; $32.4 \%$ of female survivors sustained genital injuries, whereas $43.9 \%$ of male survivors had genital or anal injuries. A significant difference between genders in terms of moderate physical injuries was observed. In $18.5 \%$ of all cases, physical injuries were documented. Moderate physical injuries included abrasions and scratches $(17.3 \%)$; more severe physical injuries included stab wounds 
Table I. Demographic and clinical characteristics of rape survivors grouped by gender

\begin{tabular}{|c|c|c|c|}
\hline & Males $(N=119)$ & Females $(N=1013)$ & \\
\hline Variable & $N(\%)$ & $N(\%)$ & $p$-value \\
\hline \multicolumn{4}{|l|}{ Age } \\
\hline Infants ( 0 - 1 years $)$ & $0(0.0 \%)$ & $8(0.8 \%)$ & \\
\hline Children (2 - 12 years) & $84(70.6 \%)$ & $187(18.5 \%)$ & $<0.001^{\ddagger}$ \\
\hline Adolescents (13 - 17 years) & $18(15.1 \%)$ & $300(29.6 \%)$ & $0.001^{+}$ \\
\hline Adults (>18 years) & $17(14.3 \%)$ & $518(51.1 \%)$ & $<0.001^{\ddagger}$ \\
\hline Total & 119 & 1013 & \\
\hline \multicolumn{4}{|l|}{ Injury } \\
\hline Genital and/or anal injury & $43(43.9 \%)$ & $299(32.4 \%)$ & $0.022^{*}$ \\
\hline Moderate physical injury & $2(2.0 \%)$ & $175(18.9 \%)$ & $<0.001^{\ddagger}$ \\
\hline Severe physical injury & $0(0.0 \%)$ & $12(1.3 \%)$ & \\
\hline \multicolumn{4}{|l|}{ Previous sexual assaults } \\
\hline Never raped before & $89(89.9 \%)$ & $806(87.8 \%)$ & 0.460 \\
\hline Raped before & $10(10.1 \%)$ & $112(12.2 \%)$ & 0.553 \\
\hline \multicolumn{4}{|l|}{ Perpetrator information } \\
\hline Perpetrator known to victim & $43(78.2 \%)$ & $442(67.0 \%)$ & 0.087 \\
\hline Perpetrator not known to victim & $12(21.8 \%)$ & $218(33.0 \%)$ & 0.087 \\
\hline \multicolumn{4}{|l|}{ Number of perpetrators } \\
\hline 1 & $68(90.7 \%)$ & $725(89.3 \%)$ & 0.710 \\
\hline 2 & $7(9.3 \%)$ & $51(6.3 \%)$ & 0.324 \\
\hline$>2$ & $0(0.0 \%)$ & $36(4.4 \%)$ & \\
\hline \multicolumn{4}{|l|}{${ }^{*} p<0.05$} \\
\hline \multicolumn{4}{|l|}{${ }^{+} p<0.01$} \\
\hline & & & \\
\hline
\end{tabular}

and fractures (1.2\%). At the time of presentation, $10.9 \%$ of female survivors tested HIV positive. None of the male survivors tested positive, possibly owing to their younger (preadolescent) age. Of the sample as a whole, $11.9 \%$ indicated that they had been raped previously. Among females, vaginal rape was reported in $93.7 \%(843 / 899)$, anal rape in $2 \%(18 / 899)$, and both vaginal and anal rape in $4.2 \%(38 / 899)$ of cases. Anal rape was reported in all male cases.

\section{Discussion}

We found similarities with the chart review by Kilian et al. ${ }^{4}$ in terms of the days of the week that most incidents were reported, rate of clinical evidence of both alcohol and drug use by survivors, involvement of multiple perpetrators, the percentage of survivors who sustained genital injuries, and the number of survivors testing HIV positive at presentation. Our average age of rape survivors is also consistent with previous Karl Bremer Rape Centre studies, indicating that young adults present most frequently to rape care facilities. ${ }^{4,10}$ An alarming finding was that, in $84.5 \%$ of cases $<15$ years old, the perpetrator was known to the survivor.

Our study provides useful comparison between male and female rape survivors. Males were considerably younger and presented with more genital and anal injuries, indicating the importance of age- and gender-specific clinical management. These findings underscore the importance of providing survivors of sexual assault with comprehensive, gendersensitive health services that support the physical and psychological consequences of the ordeal. ${ }^{6}$ Achieving this goal would be aided by increased governmental involvement combined with increasing the number of holistic post-rape care centres countrywide, including mental health support services. Furthermore, increased public awareness of the availability of post-rape care services may result in greater reporting and treatment of rape survivors.
References

1. South African Police Service Annual Report. Crime situation in South Africa. http:// www.saps.gov.za/saps_profile/strategic_framework/annual_report/2008_2009/2_crime_ situation_sa.pdf (accessed 16 February 2010).

2. Criminal Law (Sexual Offences and Related Matters) Amendment Act, 2007. Pretoria: Government Printer, 2007.

3. Vetten L, Haffejee S. Gang rape: a study in inner-city Johannesburg. SA Crime Quarterly 2005; 12: 31-36.

4. Kilian S, Suliman S, Fakier N, Seedat S. Rape survivors and the provision of HIV postexposure prophylaxis. S Afr Med J 2007; 97(8): 585-586

5. Chivers-Wilson KA. Sexual assault and posttraumatic stress disorder: a review of the biological, psychological and sociological factors and treatments. McGill J Med 2006; 9(2): 111-118.

6. Mahoney D. Preventing post-rape psychopathology (Prevention in Action). Clin Psychiatry News 2008; 36(10): 32.

7. Guidelines for Medico-legal Care of Victims of Sexual Violence. Geneva: World Health Organization, 2003

8. Christofides NJ, Muirhead D, Jewkes RK, Penn-Kekana L, Conco DN. Women's experiences of and preferences for service after rape in South Africa: interview study. Br Med J 2006; 332: 209-213.

9. Carries S, Muller F, Muller FJ, Morroni C, Wilson D. Characteristics, treatment, and antiretroviral prophylaxis adherence of South African rape survivors. J Acquir Immune Defic antiretroviral prophylaxis

10. Bello M, Pather M. Profile of rape victims attending the Karl Bremer Hospital Rape Centre, Tygerberg, Cape Town. SA Fam Pract 2008; 50(6): 46 .

Accepted 12 March 2010. 